\title{
Post Traumatic Pseudoaneurysm of Left Anterior Descending Artery Presenting as Acute Coronary Syndrome
}

\author{
Saptarshi Biswas ${ }^{\mathrm{a}, \mathrm{e}}$, Boris Hristov ${ }^{\mathrm{b}}$, Sudhakar Kinthala ${ }^{\mathrm{c}}$, Sunil Abrol ${ }^{\mathrm{d}}$
}

\begin{abstract}
Penetrating cardiac injuries are highly lethal and carry high mortality rate. Both blunt and penetrating cardiac injuries in patients who survive are known to present with well-known sequelae that often appear days to weeks after the initial insult. In the literature there have been documented cases of cardiac injury induced myocardial infarction, ventricular aneurysms, valvular dysfunction and even fistulous tracts between the coronary vessels and chamber. Although the most commonly injured vessel is the left anterior descending (LAD) coronary artery, traumatic injuries to the left coronary artery result in early death in the majority of cases. We present a unique case of LAD pseudo aneurysm and stenosis presenting as acute coronary syndrome (ACS) months after the initial penetrating cardiac injury successfully managed by stenting. There are only few isolated case reports of coronary artery pseudoaneurysm following penetrating chest trauma published in English literature.
\end{abstract}

Keywords: Acute coronary syndrome; Left anterior descending artery; Cardiac trauma; Post traumatic pseudoaneurysm

\section{Introduction}

Penetrating cardiac injuries are highly lethal and carry high mortality rate that can be as high as $80 \%$ [1]. Both blunt and penetrating cardiac injuries, in patients who survive, are known to present with well-known sequelae that often appear days to weeks after the initial insult [2-4]. In the literature there

Manuscript submitted December 27, 2018, accepted January 15, 2019

aDepartment of Trauma, Acute Care Surgery and Surgical Critical Care, Forbes Hospital, Allegheny Health Network, Monroeville, PA, USA

bDepartment of Surgery, Florida International University School of Medicine, FL, USA

'Guthrie Robert Packer Hospital, Sayre, PA, USA

${ }^{\mathrm{d} D e p a r t m e n t}$ of Cardiothoracic Surgery, NYU Winthrop Hospital, Mineola, NY 11501, USA

${ }^{\mathrm{e} C}$ Corresponding Author: Department of Trauma, Acute Care Surgery and Surgical Critical Care, Forbes Hospital, Allegheny Health Network, Monroeville, PA, USA. Email: saptarshibiswas@comcast.net

doi: https://doi.org/10.14740/cr825 have been documented cases of cardiac injury induced myocardial infarction, ventricular aneurysms, valvular dysfunction and even fistulous tracts between the coronary vessels and chamber $[5,6]$. Although the most commonly injured vessel is the left anterior descending (LAD) coronary artery, traumatic fistulas appear more often in the right coronary vessels. This is largely due to the fact that initial injuries to the left coronary artery result in early death in the majority of cases. Also the right ventricle and atrium are usually the recipients of fistula tracts due to their anterior location.

We present a unique case of LAD pseudo aneurysm and stenosis presenting as acute coronary syndrome (ACS) months after the initial penetrating cardiac injury successfully managed by stenting. There are only few isolated case reports of coronary artery pseudoaneurysm following penetrating chest trauma published in English literature [7-9].

\section{Case Report}

A 32-year-old African American male, brought in as an activated trauma by emergency medical service (EMS), presented with shortness of breath and left-sided chest pain. His vitals on admission were temperature $(\mathrm{T}) 36.7^{\circ} \mathrm{C}$; heart rate (HR) 92/min; blood pressure (BP) 145/82 mm Hg: and respiratory rate (RR) $22 / \mathrm{min}$. He was alert and oriented in time, person and place. He presented with mild dyspnea and clinical examination revealed a small puncture wound on the left anterior chest wall caused by an icepick (as per the patient). A 36 French chest tube was placed in the trauma bay under sterile conditions for diminished breath sounds on auscultation (Fig.1). He underwent a computed tomography (CT) scan following the chest tube (Fig. 2). His admission labs included complete blood count (CBC) and basic metabolic panel (BMP) which were within normal limits. His drug screen was positive of marijuana and negative for cocaine. A routine electrocardiogram (EKG) was performed on admission (Fig. 3). Past history included asthma and seizure disorder. He was a social drinker, smoker with occasional marijuana use and was involved in a MVA in 2009 resulting in a right shoulder injury.

On the first day of admission his creatine kinase (CK) was 909 and troponins were 0.019 , the coagulation profile were normal (international normalized ratio (INR) 1.0; prothrombin time (PT) 11.4; partial thromboplastin time (PTT) 24.4). A 


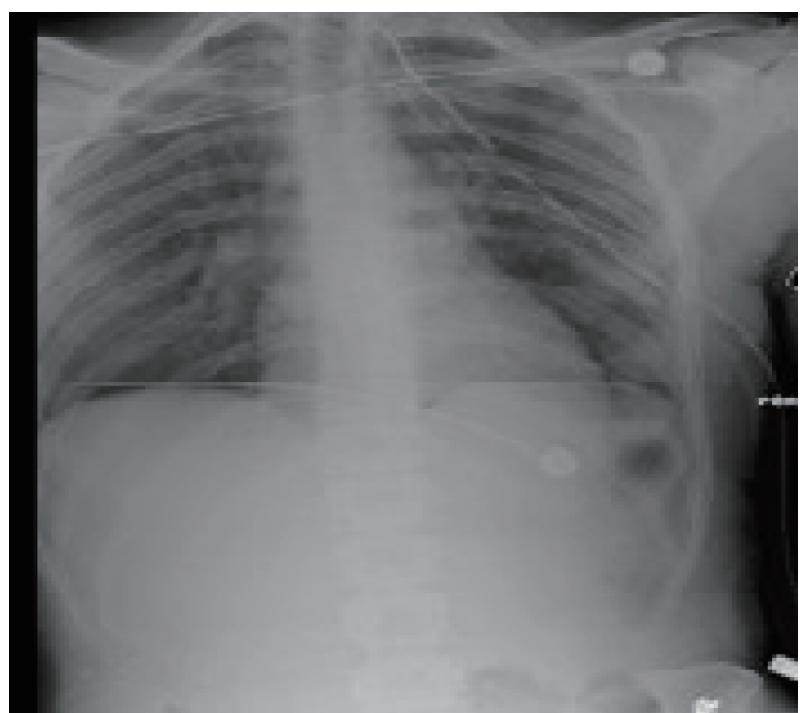

Figure 1. Initial presenting chest X-ray following chest tube insertion.

repeat CT scan of the thorax showed only a small consolidation on the left lower lobe of the lung with no hemorrhage or pericardial effusion.

The chest tube was placed off suction on hospital day 3, and without any evidence for air leak was removed on hospital day 4. On hospital day 5 he had complaints of chest pain. Chest $\mathrm{X}$-ray repeated that day showed a small apical pneumothorax. The patient was subsequently discharged following a Chest Xray on hospital day 7 which showed an unremarkable cardiopulmonary silhouette with no evidence of pneumothorax.

The patient returned 13 months later to the emergency department (ED) complaining of acute chest pain. The pain was sharp, squeezing in nature, severe in intensity, substernal in distribution, associated with nausea, dizziness, diaphoresis exacerbated by exertion. According to the patient he had several of these episodes over the last few months. His admission vitals were: T $37^{\circ} \mathrm{C}$; HR 77/min; BP 116/95mm Hg; RR 20/ min and $\mathrm{O}_{2}$ Sat $100 \%$.

EKG (Fig. 4) showed ST elevation in the precordial leads and minimal ST elevation in the inferior leads without reciprocal changes. The patient was diagnosed as acute coronary syndrome (ACS) and started on aspirin and scheduled for emergent cardiac catheterization.

He underwent left heart catheterization with ventriculography, bilateral coronary angiography and peripheral angiography via the femoral vessels (Fig. 5).

Hemodynamic assessment demonstrated no systemic hypertension and a normal left ventricular end diastolic pressure (LVEDP). Analysis of the regional contractile function demonstrated apical akinesis. Global left ventricular function was moderately depressed with the ejection fraction (EF) ranging between $40-45 \%$. Coronary circulation was left dominant with one vessel disease (LAD). The mid portion of the LAD revealed a $60-70 \%$ stenosis with a small post stenotic aneurysmal dilatation with two filling defects present suggestive of scar tissue or thrombus. There was TIMI III flow along the vessel. The left main, proximal LAD, circumflex and right

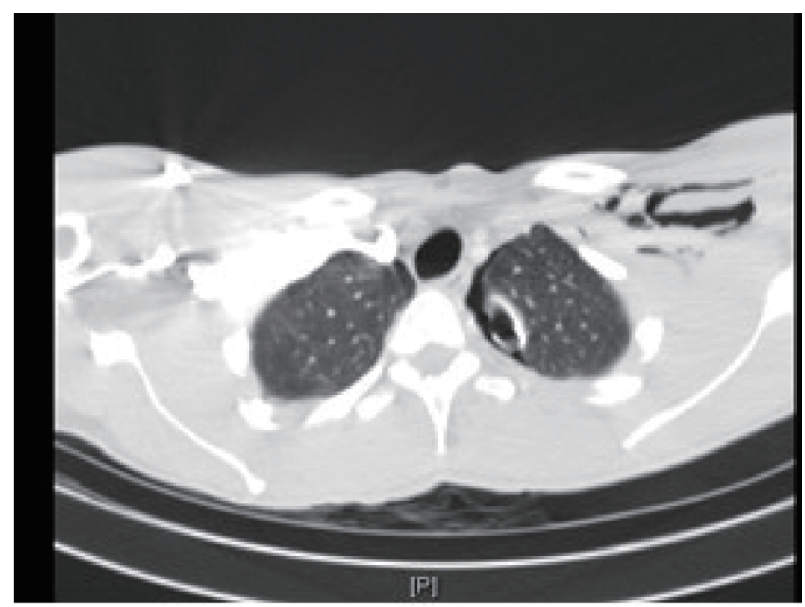

Figure 2. CT scan on initial admission demonstrating left-sided subcutaneous air and small residual pneumothorax with chest tube in place.

coronary artery (RCA) were all reported as normal.

Left heart catheterization was done using an Expo 6Fr pigtail catheter which was advanced across the aortic valve and LVEDP was recorded. Ventriculography was performed using power injection of contrast agent and imaging done using a right anterior oblique (RAO) projection. Post ventriculography left ventricular pressure (LVP) was recorded along with the aortic pressure. Right and left coronary angiography was performed in multiple projections using hand injection of contrast. Peripheral angiography was done via the right femoral artery access and angiography was obtained in the RAO projection using a digital subtraction technique.

The patient was admitted to the coronary care unit (CCU) and placed on integrilin drip $2 \mathrm{~h}$ after the removal of the femoral sheath. ASA and Plavix were started. Echocardiography was performed to evaluate cardiac structure and function.

The patient was taken back to the Cardiac Cath Lab 3 days later after discussion with cardiac surgery regarding options, and a balloon angioplasty was performed on the $70 \%$ stenotic lesion and post stenotic scar tissue in the mid LAD. An Abbott whisper 0-014 $190 \mathrm{~cm} \mathrm{Hi} \mathrm{Torque} \mathrm{wire} \mathrm{and} \mathrm{Asahi-Miraclebros}$ $3180 \mathrm{~cm}$ wire were initially tried unsuccessfully to cross the lesion. Eventually an Abbott whisper $0.014 \times 300 \mathrm{~cm} \mathrm{Hi}$ Torque wire was used to cross the LAD lesion. An intravascular angioplasty was performed using a maverick OTW 1.5 $\times 9 \mathrm{~mm}$ balloon with two inflations and a maximum inflation pressure of $8 \mathrm{~atm}$. During this procedure a new Asahi Grand Slam $300 \mathrm{~cm}$ wire was advanced across the lesion followed by a NC quantum $2.5 \times 12 \mathrm{~mm}$ balloon with two inflators and a maximum inflation pressure of $10 \mathrm{~atm}$. Finally a Xience Xpedition $3.5 \times 15 \mathrm{~mm}$ drug eluting stent was placed across the lesion and deployed at a maximum inflation pressure of 9 atm.

Intravascular ultrasonography (USG) (Fig. 6) was performed using a $40 \mathrm{MHz}$ Atlantis SR Pro $3.6 \mathrm{~F} \times 135 \mathrm{~cm}$ catheter over a previously placed guidewire. Based on the results of this study the stent was judged to be under expanded and additional balloon inflations were performed. Balloon angioplasty (Fig. 7a-c) were repeated using a NC Quantum $3.25 \times$ $12 \mathrm{~mm}$ balloon with one inflation and a maximum inflation 


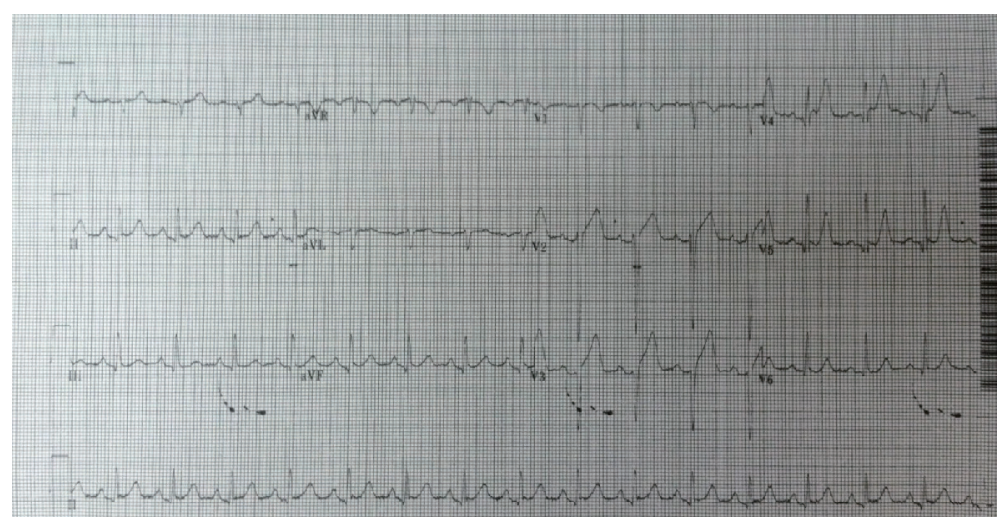

Figure 3. Initial EKG on first admission.

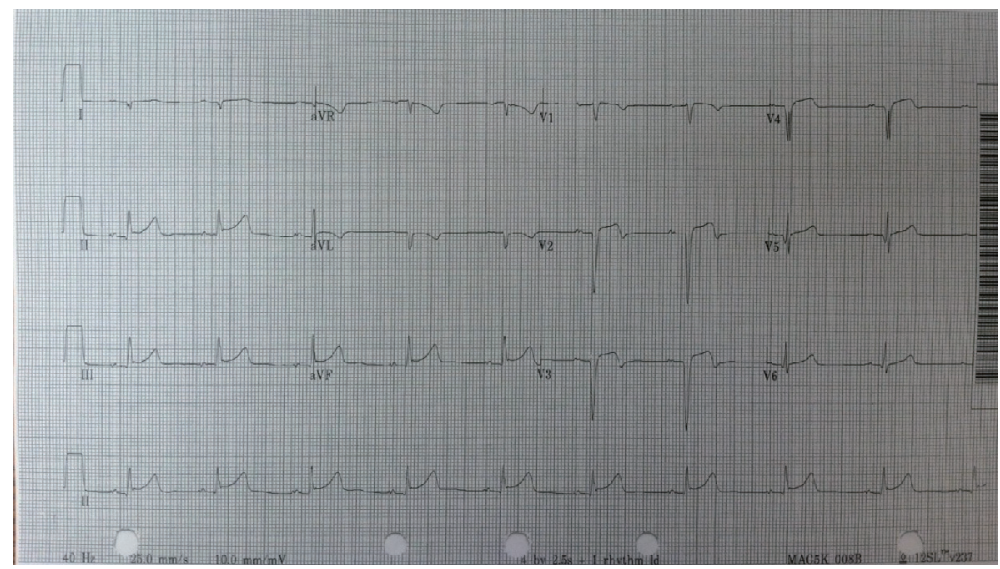

Figure 4. EKG at second admission demonstrating ST elevation.

pressure of $14 \mathrm{~atm}$, followed by a NC Trek $3.5 \times 8 \mathrm{~mm}$ balloon with one inflation and a maximum inflation pressure of $12 \mathrm{~atm}$. The resulting stenosis was zero.

The patient underwent a left coronary angiography 3 days after the second intervention. An Expo 6F FL4 catheter was positioned in the vessel ostium under fluoroscopic guidance. Angiography was performed in multiple projections using hand injection of contrast. There was no angiographic evidence of significant restenosis within the previously stented segment (Fig. 8).

\section{Discussion}

Massive penetrating cardiac injury causes significant cardiac chamber damage with often the victim unable to make it to the trauma bay alive. The most common clinical presentations include hemorrhage and pericardial tamponade $[2,10]$.

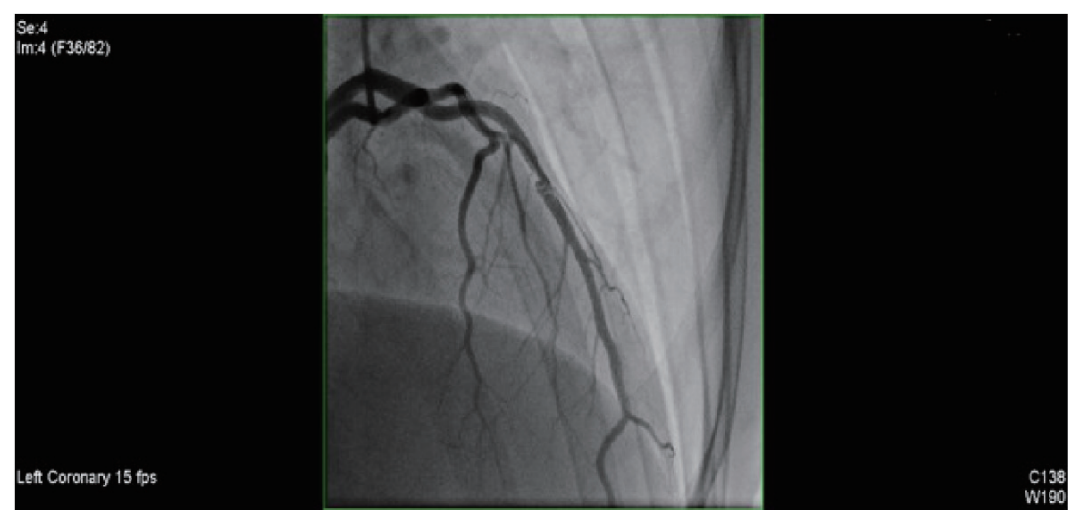

Figure 5. Initial cardiac catheterization. 


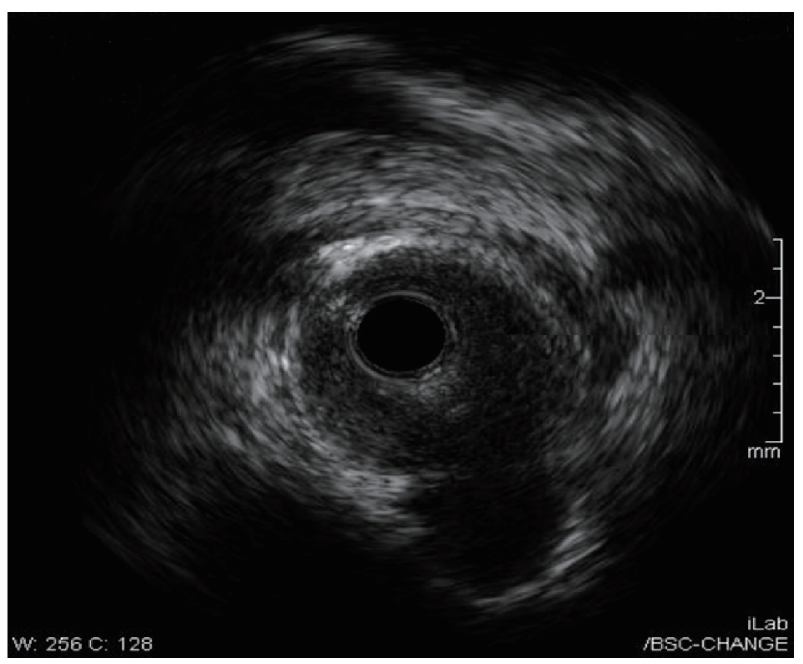

Figure 6. Intravascular USG showing pseudoaneurysm.

Interestingly, despite the fatal nature of the penetrating cardiac injury approximately $70 \%$ of the patients do not show symptoms of cardiac injury [11]. Penetrating cardiac trauma is known to cause myocardial infarction, coronary laceration, and AV fistula, coronary injury with aneurysm, pericardial tamponade, ventricular aneurysms, fistula formation, valvular or papillary muscle laceration and foreign body retention [12].

Aneurysm of the LAD coronary artery after chest trauma is extremely rare [5]. There are isolated cases reports documenting fistulous tract between LAD and coronary chambers known as coronary cameral fistulae (CCF) [6]. In addition, there have been rare reported cases of iatrogenically created coronary artery aneurysm post Coronary artery bypass graft (CABG) [13].

An aneurysm is defined as $>1.5$ times normal arterial diameter. Unlike a true aneurysm, which involves all of the layers of the arterial wall, pseudoaneurysms involve only one or more layers of the vessel wall [14]. The incidence and course of coronary artery pseudoaneurysms are not exactly known [15]. False aneurysms can result in rupture, bleeding, tamponade and myocardial infarction which may be lethal [15].

Coronary artery injury is rare with some reports citing an incidence of $3.1-4.4 \%$ of penetrating cardiac injury $[2,4,16]$ and often requires surgical or interventional treatment. LAD is
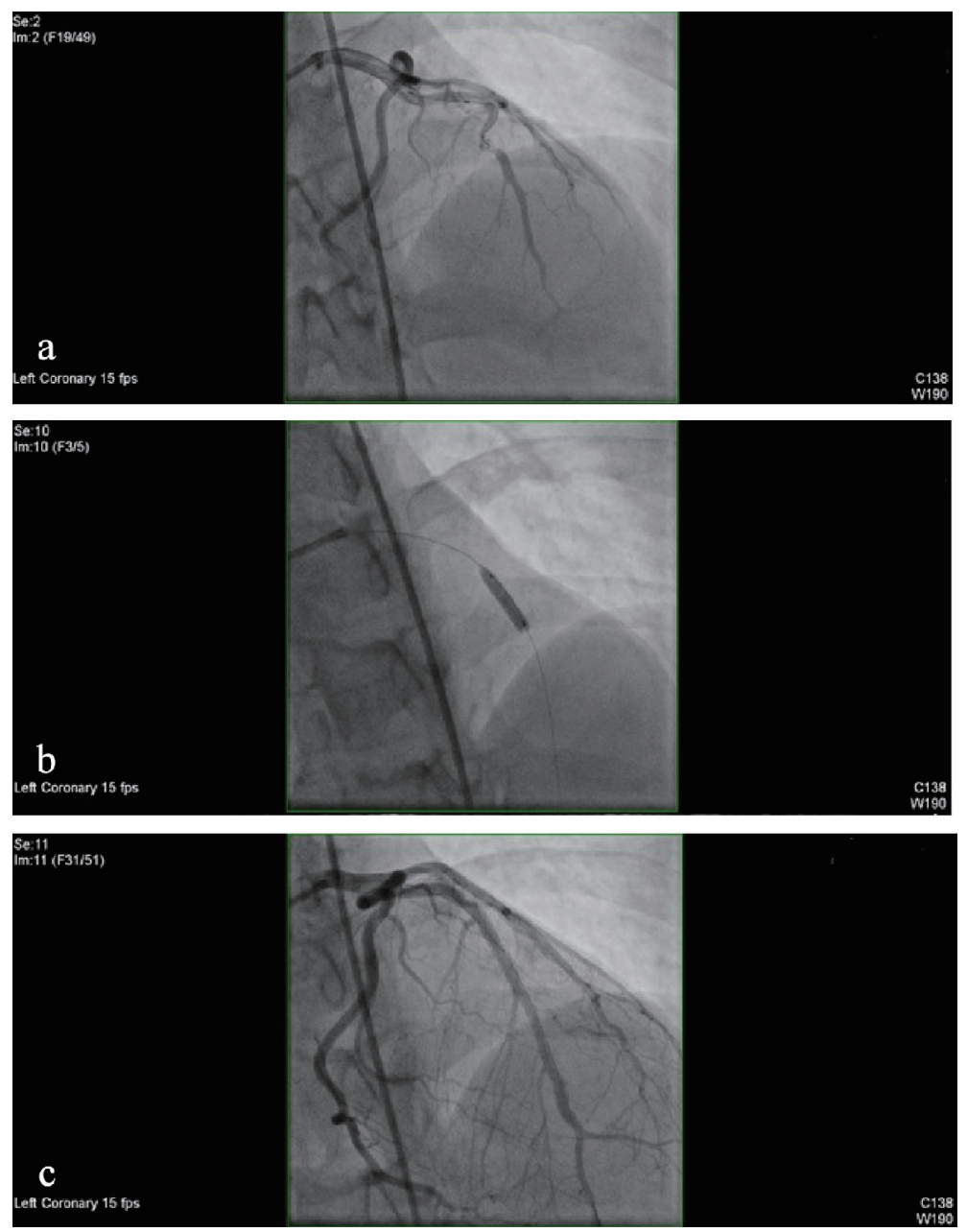

Figure 7. (a) Coronary angiography showing stenosis. (b) Balloon angioplasty. (c) No stenosis present in the previously balloon angioplasty and stented segment. 


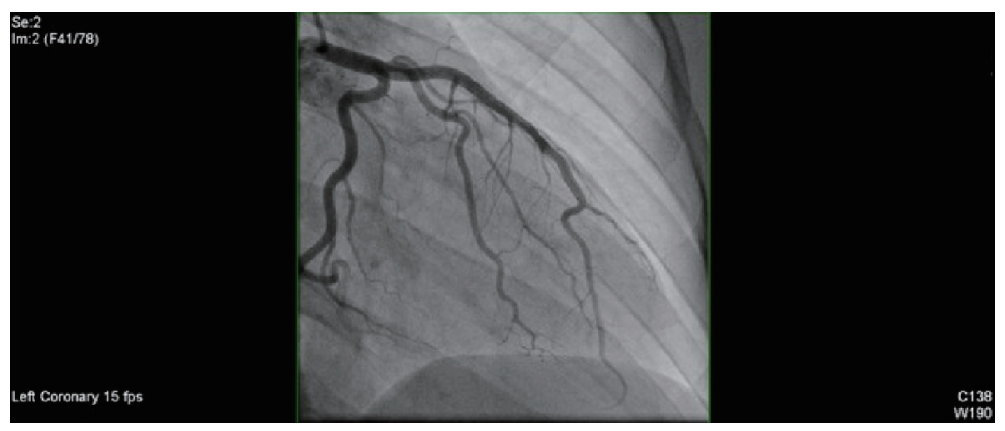

Figure 8. Left coronary angiography 3 days after the second intervention showing no restenosis.

the most frequently involved vessel followed by RCA $[2,17]$.

Differentiation between a true and false aneurysm can be determined from clinical presentation or by using conventional angiography [18]. Intravascular ultrasound or electron beam computer tomography may help in making an accurate diagnosis complimenting angiography $[19,20]$. Penetrating cardiac injuries in the vicinity of the coronary arteries should be repaired with pledgeted mattress sutures. Small peripheral coronary arteries can be ligated, although the larger ones should be repaired due to their supply to a large portion of myocardium $[2,21]$.

Currently there are no evidence based guidelines on the treatment modality for coronary pseudoaneurysms due to their relative rarity. Size, morphology, location of the lesion [9], as well as surgical risk are the initial determinants of treatment modality.

As percutaneous coronary intervention has developed along with newer adjunctive pharmacology, percutaneous coronary intervention (PCI) is used not only for simple coronary lesions but also as the treatment of choice for more complex coronary artery pathologies. This includes coronary aneurysms, pseudoaneurysms and perforations.

Coronary artery aneurysms can be managed successfully by using PTFE-coated stents or autologous vein grafts for large proximal vessels, provided that the stents can be delivered to the site $[22,23]$. Percutaneous coil embolization has often been used for coronary artery false aneurysms [22] and coronary perforation [24].

For patients with coronary artery disease needing stent placement the current stent options are drug eluting and bare metal stents. Large randomized trials have shown that while late (greater than 30 days) re-stenosis is seen more frequently in bare metal stents, overall mortality rates between the two types of stents are not statistically different [25].

For coronary aneurysms and perforations the stent of choice to use is a PTFE covered stent, especially in the large epicardial arteries involving the proximal and mid segments [26]. These stents will effectively seal any active or potential perforation with a success rate of up to $91 \%$ being reported [22]. Covered stents have the disadvantage of being more bulky and more difficult to place and have been shown to have a higher rate of early re-stenosis in the first 30 days (10.3\% vs. $3.4 \%$ ) [27]. This necessitates long-term antiplatelet therapy for at least 1 year.

Other options for perforations include bare metal stents with narrow struts [28], and if stenting cannot be achieved surgical intervention can be attempted but with a reportedly higher morbidity and mortality rate [29].

\section{Conclusions}

Of the various modalities of management of ACS we have opted for interventional management by placement of stent. The second line of treatment option (in case of a failed stent) was to go for CABG. The patient responded well by showing clinical improvement and the follow-up echocardiogram showed improvement of EF from $40 \%$ at admission to $60 \%$ following stent placement.

Based on the patient's relatively young age and lack of associated systemic risk factors there is an insignificant chance of atherosclerotic disease as the cause of the ACS. In addition, the isolated pseudoaneurysm with a scar tissue and stenosis of the LAD in contrast to otherwise healthy coronary vessels provides strong evidence that this case of ACS was result of penetrating cardiac injury and not a coronary vessel disease.

We conclude that in the context of cardiac trauma, either penetrating and/or blunt, should be considered as one of the possible causes of ACS in otherwise young patients presenting to the emergency department.

\section{References}

1. Sheikhi MA, Asgari M, Firouzabadi MD, Zeraati MR, Rezaee A. Traumatic left anterior descending coronary artery-right ventricle fistula: a case report. J Tehran Heart Cent. 2011;6(2):92-94.

2. Firozi A, Shafee O, Farsavian A, Sanati H, Shakerian F, Kiani R, Zahedmehr A, et al. Traumatic pseudoaneurysm of left anterior descending artery caused by thoracic stab thoracic stab wound treated with coil. J Cardiovasc Dis Diagn. 2014;2:173

3. Cheng TO, Adkins PC. Traumatic aneurysm of left anterior descending coronary artery with fistulous opening into left ventricle and left ventricular aneurysm after stab wound of chest. Report of case with successful surgical repair. Am J Cardiol. 1973;31(3):384-390.

4. Demetriades D, van der Veen BW. Penetrating injuries of the heart: experience over two years in South Africa. J Trauma. 1983;23(12):1034-1041. 
5. Bjorn-Hansen LS, Thomassen AR, Nielsen TT. Aneurysm of the left anterior descending coronary artery after chest trauma. Eur Heart J. 1989;10(2):177-179.

6. Tsushima Y, Haapanen A, Dean PB, Mikkola J, Saraste M. Traumatic fistula between the left anterior descending coronary artery and a left ventricular pseudoaneurysm. Cardiovasc Intervent Radiol. 1996;19(4):272-274.

7. Xing J, Li S, Zhang L, Yang Y, Duan Y, Li W, Zhou Y. Fatal delayed cardiac tamponade due to rupture of micropseudoaneurysm of left anterior descending coronary artery following stab to the chest. Cardiovasc Pathol. 2015;24(4):241-243.

8. Bartoloni G, Trio F, Bartoloni A, Giorlandino A, Pucci A. A fatal stab wound causing selective injury to the left anterior descending coronary artery, myocardial infarction and delayed cardiac tamponade. Forensic Sci Int. 2013;229(1-3):e16-18.

9. Hong SJ, Lim DS, Kim YH, Shim WJ, Park CG, Seo HS, Oh DJ, et al. Chest stab wound-related coronary artery pseudoaneurysm sealed with a polytetrafluoroethylenecovered stent. Heart Vessels. 2005;20(5):233-235.

10. Harman PK, Trinkle JK. Injury to the heart. In: Moore EE, Mattox KL, Feliciano DV, editors. Trauma. 2nd ed. Norwalk: Appleton and Lange; 1991.

11. Jimenez E, Martin M, Krukenkamp I, Barrett J. Subxiphoid pericardiotomy versus echocardiography: a prospective evaluation of the diagnosis of occult penetrating cardiac injury. Surgery. 1990;108(4):676-679; discussion 679-680.

12. Wilson WC, Grande CM, Hoyt DB. Trauma: Critical Care, Volume 2; Chapter 19, page 341.

13. Minden HH, Just S, Butter C. Acute large pseudoaneurysm of the left anterior descending artery following bypass surgery: combined percutaneous approach with a PTFE-coated coronary stent and coil embolization. J Invasive Cardiol. 2007;19(1):E15-18.

14. Behera C, Garudadhri GV, Kulbhushan Sunil. Fatal pseudo aneurysm in common femoral artery. A case report. J Indian Acad Forensic Med. 2011;33:80-82.

15. Chen D, Chang R, Ho AT, Frivold G, Foster G. Spontaneous resolution of coronary artery pseudoaneurysm consequent to percutaneous intervention with paclitaxeleluting stent. Tex Heart Inst J. 2008;35(2):189-191; discussion 192.

16. Rea WJ, Sugg WL, Wilson LC, Webb WR, Ecker RR. Coronary artery lacerations; an analysis of 22 patients. Ann Thorac Surg. 1969;7(6):518-528.

17. Symbas PN. Cardiothoracic Trauma. Philadelphia: WB Saunders, USA. 1991.

18. Munera F, Soto JA, Palacio D, Velez SM, Medina E. Diagnosis of arterial injuries caused by penetrating trauma to the neck: comparison of helical CT angiography and conventional angiography. Radiology. 2000;216(2):356362.

19. Saad NE, Saad WE, Davies MG, Waldman DL, Fultz PJ, Rubens DJ. Pseudoaneurysms and the role of minimally invasive techniques in their management. Radiographics. 2005;25(Suppl 1):S173-189.

20. Ugolini P, Mousseaux E, Hernigou A, Gaux JC. Infectious pseudoaneurysms suspected at echocardiography: electron-beam CT findings. Radiology. 2000;217(1):263269.

21. Pons F, Lang-Lazdunski L, de Kerangal X, Chapuis O, Bonnet PM, Jancovici R. The role of videothoracoscopy in management of precordial thoracic penetrating injuries. Eur J Cardiothorac Surg. 2002;22(1):7-12.

22. Briguori C, Nishida T, Anzuini A, Di Mario C, Grube E, Colombo A. Emergency polytetrafluoroethylene-covered stent implantation to treat coronary ruptures. Circulation. 2000;102(25):3028-3031.

23. Maybrook RJ, Sharma S, Gupta K, Wiley M, Parashara D. Percutaneous closure of a coronary artery-to-vein graft anastomotic pseudoaneurysm presenting as acute coronary syndrome after recent coronary artery bypass grafting. Tex Heart Inst J. 2015;42(3):265-269.

24. Yeo KK, Rogers JH, Laird JR. Use of stent grafts and coils in vessel rupture and perforation. J Interv Cardiol. 2008;21(1):86-99.

25. Stettler C, Wandel S, Allemann S, Kastrati A, Morice MC, Schomig A, Pfisterer ME, et al. Outcomes associated with drug-eluting and bare-metal stents: a collaborative network meta-analysis. Lancet. 2007;370(9591):937948.

26. Al-Mukhaini M, Panduranga P, Sulaiman K, Riyami AA, Deeb M, Riyami MB. Coronary perforation and covered stents: an update and review. Heart Views. 2011;12(2):6370 .

27. Stankovic G, Colombo A, Presbitero P, van den Branden F, Inglese L, Cernigliaro C, Niccoli L, et al. Randomized evaluation of polytetrafluoroethylene-covered stent in saphenous vein grafts: the Randomized Evaluation of polytetrafluoroethylene COVERed stent in Saphenous vein grafts (RECOVERS) Trial. Circulation. 2003;108(1):3742.

28. Karabulut A, Topcu K. Coronary perforation due to sirolimus-eluting stent's strut rupture with post-dilatation. Kardiol Pol. 2011;69(2):183-186; discussion 187.

29. Eggebrecht H, Ritzel A, von Birgelen C, Schermund A, Naber C, Bose D, Baumgart D, et al. Acute and longterm outcome after coronary artery perforation during percutaneous coronary interventions. Z Kardiol. 2004;93(10):791-798. 